\title{
Understanding High Performance in Late Second Language (L2) Acquisition-What Is the Secret? A Contrasting Case Study in L2 French
}

\author{
Fanny Forsberg Lundell * and Klara Arvidsson
}

Citation: Forsberg Lundell, Fanny, and Klara Arvidsson. 2021.

Understanding High Performance in Late Second Language (L2)

Acquisition-What Is the Secret? A Contrasting Case Study in L2 French. Languages 6: 32. https://doi.org/ 10.3390/languages6010032

Received: 16 November 2020

Accepted: 13 February 2021

Published: 19 February 2021

Publisher's Note: MDPI stays neutral with regard to jurisdictional claims in published maps and institutional affiliations.

Copyright: (c) 2021 by the authors. Licensee MDPI, Basel, Switzerland. This article is an open access article distributed under the terms and conditions of the Creative Commons Attribution (CC BY) license (https:// creativecommons.org/licenses/by/ $4.0 /)$.
Department of Romance Studies and Classics, Stockholm University, SE-10691 Stockholm, Sweden; klara.arvidsson@su.se

* Correspondence: fanny.forsberg.lundell@su.se

\begin{abstract}
Adult L2 acquisition has often been framed within research on the Critical Period Hypothesis, and the age factor is one of the most researched topics of SLA. However, several researchers suggest that while age is the most important factor for differences between child and adult SLA, variation in adult SLA is more dependent on social and psychological factors than on age of onset. The present qualitative study investigates the role of migratory experience, language use/social networks, language learning experience, identity and attitudes for high performance among Swedish L1 French L2 users in France. The study constitutes an in-depth thematic analysis of interviews with six high-performing individuals and four low-performing individuals. The main results show that the high performers differ from the low performers on all dimensions, except for attitudes towards the host community. High performers are above all characterized by self-reported language aptitude and an early interest in languages, which appears to have led to rich exposure to French. Also, they exhibit self-regulatory behaviors and attribute importance to being perceived as a native speaker of French-both for instrumental and existential reasons.
\end{abstract}

Keywords: migration; L2 French; adult SLA; high performance; individual factors

\section{Introduction}

It is a well-known fact, both from research and our everyday experiences, that adult language learners differ remarkably in how well they come to master additional languages. Hyltenstam (2018) argues that while the difference between pre-puberty and post-puberty learners in second language acquisition is largely related to maturational constraints, differences in outcomes among adult second language learners are affectedo a much larger extent by factors such as aptitude, motivation and practice. For instance, Granena and Long (2013) find that after age, aptitude is the strongest explanatory factor for adult SLA. However, several researchers argue for the importance to study additional individual factors to understand the complexity of adult SLA and have long stressed the need to examine the effect of cognitive, affective and social factors among adult second language learners (Douglas Fir Group 2016; Kinsella and Singleton 2014; Moyer 2014; Muñoz and Singleton 2011). However, few studies have set out to investigate this in a migratory context, where circumstances for high-level L2 attainment are perhaps the most advantageous.

Since the classical study of Naiman et al. (1978) on The Good Language Learner, conducted on 72 secondary school pupils in Canada, researchers have from time to time come back to the question of what characterizes successful second language learners. A recent attempt was made by Muñoz (2014), who also searched for characteristics of high-achievers vs. low-achievers in a formal learning context among university students of English. She considered the learners' starting age, but also other contextual and affective factors. Her study shows that starting age is important for some, but that aptitude, motivation and intensive language contact seem to play important roles for others. She concludes that 
second language long-term attainment is most likely the result of interaction between many factors. Within the realm of adult second language acquisition, a few attempts have been made to single out what characterizes exceptional adult language learners. In a qualitative meta-analysis, Moyer (2014) concludes that "learner engagement and self-regulation" (p. 418) characterize the adult learners who have ended up sounding nativelike in their L2 despite a late age of onset. As mentioned above, few studies are set in a migratory context, yet research conducted in a Study Abroad context provides evidence for the importance of social and psychological factors. For example, Mitchell et al. (2017) presented in-depth case studies of Anglophone participants who made the most progress in their target language (French or Spanish). The authors observed that relationships sustained in the target language promoted L2 development as well as personality characteristics such as flexibility and social adaptability for some, and a "strategic vision of the L2 self" (p. 245) for others. These results could potentially also have a bearing on the results of long-term residents abroad, who are the participants in focus of the present study.

This study is part of the mixed method research project "Global Mobility and Adult Second Language Acquisition: the Importance of Social and Psychological Factors" (Vetenskapsrådet 2017-01196). It constitutes a qualitative follow-up study to a preceding quantitative study (Forsberg Lundell et al. forthcoming) (see Section 2.1). The aim of the present qualitative, in-depth study is to investigate social and psychological factors in a more detailed manner, in order to understand what factors facilitate high L2 performance later in life. This is done through a thematic analysis of deep interviews with six linguistically highperforming and four linguistically low-performing individuals. A fundamental premise for the present study is that adult L2 acquisition can be explained by the interaction of multiple factors. Accordingly, the paper takes a bird's eye view in mapping several factors. This approach allows for a comparison of the relative weight of these factors, but has the inconvenience that it does not allow for any in-depth study of each factor. The research question for the present study is: What factors emerge that are decisive for attaining very high levels of second language proficiency in late L2 acquisition, and more specifically in the migratory context of France?

\section{Background}

In the present section, we will first account for the preceding quantitative study and the social and psychological factors identified as most important in that study. Then, we will provide a literature review of the factors that were identified as relevant in this follow-up study.

\subsection{The Preceding Quantitative Study: Forsberg Lundell et al. (forthcoming)}

The quantitative study preceding the present study investigated how individual factors relate to perceived nativelikeness (cf. Abrahamsson and Hyltenstam 2009) in late L2 learners of French (Swedish L1) $(\mathrm{N}=62)$ with a minimum length of residence (LOR) of 5 years in France. Perceived nativelikeness was operationalized as the number of native speaker evaluators out of 10 perceiving a person to be a native speaker of their own language. The individual factors included were:

- $\quad$ Language aptitude, measured by the LLAMA test (Meara 2005). This test includes four different components of aptitude: vocabulary learning (LLAMA B), sound recognition (LLAMA D), sound-symbol correspondence (LLAMA E) and grammatical inferencing (LLAMA F).

- Personality, measured by the Multicultural Personality Questionnaire (MPQ) (van der Zee et al. 2013). The MPQ measures an individual's capacity to adjust in a new cultural setting.

- Acculturation, measured by the Vancouver Index of Acculturation (VIA) (Ryder et al. 2000), measuring cultural orientation to heritage and host cultures, in our case the dimensions VIA Sweden and VIA France. 
- Target language engagement, measures the language use of the participants, questionnaire developed by (McManus et al. 2014).

- Social networks, measures the number of social relations in the L2 of the participants, questionnaire developed by (McManus et al. 2014).

A hierarchical multiple regression analysis showed that both the subtest LLAMA D (targeting phonetic memory) and VIA Sweden (one of the acculturation variables) were reliable predictors of perceived nativelikeness and the effects were medium-sized in relation to other studies on individual factors. The results mean that the better the phonetic memory of a person and the weaker his/her affiliation with Sweden, the higher the likelihood for him/her being perceived as a native speaker. In addition, the study also showed that the participants in the present population were generally high-proficient speakers. They showed little individual variation on a productive collocation test, a test developed to gauge high levels of L2 proficiency (Forsberg Lundell et al. 2018). Many scored at ceiling on this test and it was accordingly not possible to include the scores from this test in the regression analysis including individual factors.

\subsection{Social and Psychological Factors Included in the Present Study}

In the preceding study, language aptitude and acculturation, investigated along other individual factors, were assessed from a quantitative perspective. However, there are certainly factors influencing the language learning trajectory that cannot be gauged easily in questionnaires. In the present study, five different psychological and social factors were selected as targets for the deep interview (described in Section 3.3). As stated above, research on long-term residents and individual factors is scarce. In the present study, factors were selected to a large extent based on the studies by Moyer $(2004,2014)$ cited above, especially Moyer (2004), which investigates long-term residents, nativelike phonology and individual factors in L2 German, both a research topic and learning context similar to ours. In addition, we also draw on findings from Study Abroad research, which also constitutes adult SLA in a naturalistic context. In this field, considerable attention has been paid to the role of individual factors for the linguistic development during Study Abroad (e.g., Mitchell et al. 2017). Some of these factors were targeted through questionnaires and tests in the quantitative study, but others, considered most apt to study through the narratives of the participants, have been added in the present study. Below, the investigated factors are defined, and relevant research results are reviewed.

\subsubsection{Migratory Experience}

The term "migratory experience" is widely used in the field of migration studies (sociology, anthropology, etc.) and has hitherto been less explored within mainstream SLA. One exception is Diskin and Regan (2015), who use "migratory experience" to refer to motive for migration in their study - they investigate whether being a chain migrant, economic migrant or cultural migrant has an impact on the acquisition of sociolinguistic competence and conclude that cultural migrants attain a more target-like use of a particularly Irish discourse marker than the other categories of migrants. In the present study, "motive for migration" is a component of migratory experience, but is not as narrowly defined. Instead, we draw on the work of De Fina and Tseng (2017) and use the term in a wider sense, namely to include the learners' experience of migrating to the host community at large, including migratory motive, occupation, social circumstances and personal experiences. An investigation of learners' migratory experience is here assumed to shed light on circumstances and experiences which may have influenced the L2 learning outcomes.

\subsubsection{Language Use/Social Networks}

Individuals vary with respect to how frequently and in what circumstances they use the target language. Several studies find that rich target language exposure and contact with native speakers is necessary to attain a native-like L2 speech. For example, in a German context, Moyer (2004) found a strong and significant correlation ( $r$. 73) between 
self-reported amount of social interaction with native speakers and degree of perceived nativelikeness. Participants were 25 immigrants from diverse nations with a mean LOR of 6 years. These results align with Dollmann et al. (2020), whose study included 1843 adolescents with immigrant background with a varying age of arrival in Germany. The authors found an especially strong effect of L2 exposure for accent-free speech in L2 German among immigrants who arrived in Germany at the age of 10 or later, indicating that L2 exposure and contact with native speakers (and higher cognitive abilities) may compensate for a later age of onset. The extent to which the adult L2 learner uses the L2 is naturally influenced by whether she uses other languages in her everyday life. Flege et al. (1997) observed that among a group of Italians who immigrated to Canada at around the age of 6 , those who reported using Italian relatively frequently in their everyday lives spoke with a significantly stronger foreign accent than Italians who rarely spoke Italian. These results are in line with Moyer's (2014) observation regarding learners who have attained nativelike levels with respect to L2 phonology. Several of them report using their L1 minimally, in addition to using the L2 frequently.

Given that an L2 learner's access to social interaction in the L2 is partly determined by her social relationships, researchers inspired by Milroy's (1980) work in sociolinguistics have also investigated L2 users' social networks as a way to understand L2 learning outcomes. Research has been carried out in a Study Abroad context where links have been found between various social network variables and various indicators of L2 performance (e.g., Dewey et al. 2013; Mitchell et al. 2017). In a migratory context, Lybeck (2002) found that those among the nine Americans who participated in the study, who forged social networks including native speakers of Norwegian were the ones who achieved higher levels of native-like pronunciation. Being married to a native speaker helped gaining access to Norwegian-speaking networks, yet the two highest performers had also created their own social ties with locals. In sum, patterns of language use and social networks thus appear to be influential in forging L2 speech.

\subsubsection{Language Learning Experience}

Just like "migratory experience", "language learning experience" is an encompassing term in the present study. In the literature, it is sometimes used only to refer to prior experience of language learning (e.g., years of formal study of the language). This aspect is included in our definition as well, but we also include the learner's subjective language learning experience, for example experiences of motivation, enjoyment, frustration and difficulties (cf. Dewaele et al. 2016). Emotional responses to the language learning process may impact the learner's inclination to invest in the language learning process (on the role of emotion, see, e.g., Dewaele et al. 2018). That self-perceived language aptitude and emotions conspire to shape an individual's motivation to invest in language learning was found by Busse and Williams (2010) and Stolte (2015). They sought to understand what characterized the relatively few anglophone students who chose to pursue advanced studies of German in England. They found that the targeted language students enjoyed language learning at school and perceived that they had an aptitude for this activity (what we call "self-reported aptitude" in our analysis). Success and ease then lead to the creation of intrinsic motivation, according to these researchers. These studies do not explain high performance directly, but are nevertheless linked to our pursuit to understand L2 learning later in life.

Last, another component of our category "language learning experience", is the extent to which the learners report agency (see, e.g., Duff and Talmy 2011) in relation to the language learning process. In language socialization research or socio-cultural theory, agency means that "learners are agents who may contest or transform as well as accommodate practices others attempt to induct them into" (Duff and Talmy 2011, p. 110). Related to the notion of agency is the concept of self-regulation (Bandura 1991), although these two stem from different theoretical traditions. Self-regulated learners have a capacity to control their behavior to improve learning (Dörnyei 2010, p. 256). 


\subsubsection{Identity}

Identity is a multi-faceted concept, which can refer to many different conceptions within the field of SLA. It is often stressed within the social sciences that people do not have one, sole identity, but rather multiple identities related to their professional status, their national affiliation, their sexual orientation, their interests and so on. As Norton (2014) acknowledges, identity has come to be viewed from a more dynamic point of view, as co-constructed rather than static or monolithic and also as a site for struggle. In the present study, the thematic analysis is driven by pre-defined categories, but it is also data driven. The identity-related questions in the interview focus on identity in terms of cultural orientations, which is how identity is conceptualized in the VIA acculturation questionnaire (Ryder et al. 2000) used in the preceding quantitative study. Identity in the present study is thus similar to what Lybeck (2002) labels "cultural identification". In her study on nine American women learning L2 Norwegian in Norway, she found that the participants who displayed a stronger cultural identification with Norway and Norwegians also attained a more targetlike pronunciation. In a similar vein, research by Gatbonton and Trofimovich (2008) has shown that ethnolinguistic affiliation has an impact on targetlike pronunciation.

Another aspect of the identity construct relates to the participants' identity as second language users. Benson et al. (2013), interested in identity development in Study Abroad, speak of second language identity as "incorporating experiences of second language learning and use in an ongoing sense of who we are" (p. 42). More precisely, their notion of linguistic self-concept will be a relevant tool to make sense of our participants' identity narratives. This notion subsumes affiliations to the different languages one knows, beliefs about language learning and self-assessment and perceptions of the self. Interestingly, Lybeck (2002) observes a connection between cultural identification and linguistic selfconcept. The participants in her study who had a strong cultural identification and those who had a weaker cultural identification displayed different linguistic self-concepts: those who had a strong cultural identification underlined the felt obligation to learn the language of the new culture. Also, they accepted that speaking this language made them feel somewhat different and their self was able to endure this slight change. Becoming a proficient L2 speaker was accordingly part of these participants' identity. This was not the case for speakers with low degrees of cultural identification.

\subsubsection{Attitudes}

The notion of "attitudes" is, similarly to "identity", a multi-faceted concept within SLA. In the present paper, "attitude" is conceptualized as "attitudes towards the target group". Attitudes towards the target group is a component both in Gardner's socio-educational model (e.g., Gardner 2006) and in Schumann's Acculturation model (Schumann 1976) and is argued by several scholars in the socio-psychological tradition to be an important aspect of the L2 learning process (MacIntyre and Charos 1996; Kormos et al. 2011). The underlying assumption in the cited models is that language learner's attitudes towards the target language group influence the extent to which she is willing to engage with the host community and the language learning process. Scholars investigating language learning in a Study Abroad context do find that the attitudes learners hold towards the target community impact their propensity to participate in social activities including members of the host community and to expand efforts to learn the target language (Isabelli-García 2006; Kinginger 2013). It thus seems relevant to include this variable in our mapping of the factors that may influence L2 attainment.

\section{Materials and Methods}

\subsection{Research Design and Procedure}

The study is based on a thematic analysis of in-depth interviews with two contrasting cases of learners. The two cases were represented by 10 learners who could be qualified linguistically high-performing and linguistically low-performing individuals on the basis of their linguistic performance in the preceding quantitative study (see Forsberg Lundell et al. 
forthcoming). These two cases will be referred to as "high performers" and "low performers". Such a contrasting approach makes it possible to single out what characteristics and experiences are specific to learners who have attained high levels of L2 proficiency (see also Muñoz 2014).

Ten participants were selected from the pool of 62 participants in the preceding quantitative study (see Section 2.1), based on their linguistic performance on the basis of (1) a productive collocation test, targeting verb-noun collocations such as commettre un crime (elaborated and validated by Forsberg Lundell et al. 2018), (2) the number of NS evaluators judging them as native speakers of French (following the procedure of Abrahamsson and Hyltenstam 2009). We used an extreme sampling strategy, meaning that we selected those participants who had obtained the highest versus the lowest scores on the two linguistic measures. We started the sampling procedure by ranking the 62 participants according to their linguistic performance and we decided to let five participants represent each case, meaning that we selected those occupying rank 1-5 and 57-62. However, it turned out that two individuals occupied rank 5. Since they had identical scores on the two linguistic measures, we decided to include them both with the consequence that the case of the "high performers" is represented by 6 individuals. With respect to the "low performers", the five individuals occupying rank 57-62 were selected for the study. The selected participants were then contacted and invited to participate in an interview with the second author. All six high performers responded and accepted, yet we were only able to reach four of the five low performers. For logistical and practical reasons, it was not possible to reach out to the "low performer" next in rank. Thus, the present study is based on interview with six high performers and four low performers.

The study received an ethical approval from the Swedish Board of Ethical Review (Regionala etikprözningsnämnden i Stockholm, Diary number 2018/2019-31/5) and was conducted in accordance with the Declaration of Helsinki.

\subsection{Participants}

The participants were two men and eight female Swedish learners of French who had had started learning French at the age of 12 or later and who had resided in Paris, France, for at least five years at the moment of the interview. Supplementary criteria for inclusion were to have finished upper secondary studies and to have Swedish as L1. As shown in Table 1 here below, there is a lot of variation in terms of length of residence (LOR), which ranges from 5 to 54 . LOR is generally longer in the high-performing group. As can be concluded from the table, the level of education and socio-economic status are very similar in the two groups.

Table 1. Description of participants.

\begin{tabular}{|c|c|c|c|c|c|c|c|}
\hline & Age & $\begin{array}{l}\text { Age of } \\
\text { Onset }\end{array}$ & $\begin{array}{c}\text { Length of } \\
\text { Residence (in Years) }\end{array}$ & $\begin{array}{c}\text { Professional } \\
\text { Orientation }\end{array}$ & LLAMA D & VIA Sweden & VIA France \\
\hline \multicolumn{8}{|c|}{ High performers } \\
\hline Margareta & n.a. & 16 & 54 & phys. ed. teacher & 25 & 6.6 & 7.3 \\
\hline Simon & 39 & 13 & 8 & medical doctor & 45 & 6 & 6.3 \\
\hline Leo & 33 & 12 & 14 & university lecturer & 55 & 7.6 & 6.4 \\
\hline Lina & 45 & 13 & 18 & university lecturer & 30 & 7 & 6.9 \\
\hline Gunilla & 58 & 13 & 38 & medical doctor & 45 & 7.8 & 7.7 \\
\hline Lovisa & 42 & 13 & 18 & business managment & 15 & 7.6 & 6.2 \\
\hline \multicolumn{8}{|c|}{ Low performers } \\
\hline Helena & 56 & 36 & 20 & teacher & 40 & 6 & 6.6 \\
\hline Ida & 30 & 12 & 6 & fashion industry & 20 & 5.7 & 4.3 \\
\hline Johanna & 39 & 18 & 5 & research & 20 & 6.4 & 6.1 \\
\hline Lea & 43 & 13 & 11 & accounting & 15 & 3 & 5.8 \\
\hline
\end{tabular}


With respect to linguistic performance, high performers scored $<27 / 30$ on the collocation test and were perceived as native speakers of French by 10 out of 10 native speaker evaluators. Low performers scored $>20 / 30$ on the collocation test and were not perceived by any of the native evaluators to be native speakers of French. Table 1 also includes the LLAMA and VIA scores of the participants. As for LLAMA D, the aptitude score referring to phonetic memory, Meara (2005) states that scores from 0-10 are classified as Poor, 15-35 as Average, 40-60 as Good and 65-75 as Outstanding. It can be concluded that three of the six high performers have Good (above average) aptitude, on the sub-test LLAMA $\mathrm{D}$, but the other three have an average aptitude. Among the low performers, only one has Good aptitude, the others being Average, in Lea's case bordering on Poor. Figures for VIA Sweden and VIA France range on a scale from 1-9. The closer to 9, the stronger the affiliation with Swedish vs. French culture. Interestingly, the low performers have in general lower degrees of affiliation with both countries/cultures.

\subsection{Interviews}

The interviews were carried out in Paris, in October 2019, by the second author. The participant was asked to choose a location for the interview: some chose to be interviewed in their home, others chose to be interviewed in a café in Paris. Before collecting the data, the subjects gave their informed consent. Each interview lasted between 50 and $65 \mathrm{~min}$ and was recorded using a Dictaphone and an iPhone. The atmosphere was relaxed, and the participants were all eager to share their experiences. The content of the interview is further described in Section 3.3. The interviews were fully transcribed by the authors in Microsoft Word and then subjected to a thematic analysis, which is described in Section 3.4. All the participants then received pseudonyms.

The semi-structured interview was conducted based on an interview script. The script contained 18 questions (three of which had follow-up questions), formulated to elicit information on the participants' biography as well as information relevant to the investigated psychological and social factors (migratory experience, social networks and language use, language learning experience, identity, and attitudes). Example questions are: "Can you please describe your social network?", "How have you experienced the language learning process?", and "Have you used any strategies to improve your French?".

\subsection{Analysis}

The transcribed interviews were submitted to a thematic analysis, which is "is a method for identifying, analyzing and reporting patterns (themes) within data" (Braun and Clarke 2006, p. 79). A "theme", according to Braun and Clarke (2006), "captures something important about the data in relation to the research question, and represents some level of patterned response or meaning within the data set" (Braun and Clarke 2006, p. 82). A thematic analysis can be data driven (concepts/categories emerge from the data) or theoretically driven (preidentified theoretical concepts/categories are used to code the data). We used the latter approach: We sought to identify themes in the data that were directly related to the five predefined categories/factors that structured the interview.

To organize the analysis, we first created one Microsoft Excel sheet for each of the two cases ("high performers" and "low performers") in which the above-mentioned categories were lined up horizontally and each individual participant representing the given case listed vertically. Then we divided the data set between us: Author1 analyzed the high performer data set (six interviews) and Author2 the low performer data set (four interviews). Each author separately performed her analysis, following the procedure described here below:

(1) We coded the data using the above-mentioned categories.

(2) We extracted data excerpts related to each category and organized these in the described Microsoft Excel sheet.

(3) Based on the Microsoft Excel sheet, we identified themes for each category. To count as a "theme", we decided that a meaning content had to occur at least in two of the 
interviews. An example theme for the category "social networks" is "socializing mainly with French people", identified in the high performer data.

(4) We went back to the data to adjust/confirm the identified themes.

(5) After having finalized the first round of analysis, we exchanged data sets and repeated the process described above. When we had finalized the second round of analysis, we compared the themes we had come up with, discussed any discrepancies, and adjusted themes accordingly.

\section{Results}

As stated in the Materials and Methods section, five categories corresponding to social/psychological factors were targeted in the interviews. The findings related to each included factor will be presented in separate sub-sections. The identified themes, for high vs. low performers, within each category, are presented in tables in each sub-section and are then subsequently discussed.

\subsection{Migratory Experience}

Within the category migratory experience, some of the themes identified in both groups related to motive for migration (see Table 2 below). In the high-performing group, a common initial motive for migration is a desire to study or work abroad, often coupled with a particular interest in France and the French language. While a romantic partner is a common final motive for migration in the high performer group, it is also common as the initial motive for migration in the low performer group. Another theme related to motive for migration in the low-performing group is that of a professional opportunity. A general impression is that in the low-performing group, circumstances of life (love and work) made them end up in France, whereas it was a conscious choice in the high-performing group. It is possible that the different motives for migration have affected the high and low performers' language learning orientation and L2 attainment, which would be in line with Diskin and Regan (2015), who found that motive for migration appeared to affect the acquisition of sociolinguistic competence.

Table 2. Identified themes in the category "Migratory experience".

\begin{tabular}{|c|c|}
\hline \multicolumn{2}{|c|}{ Category: Migratory Experience } \\
\hline High Performers' Themes & Low Performers' Themes \\
\hline $\begin{array}{c}\text { initial motive for migration: wish to study abroad, } \\
\text { interest in France/French }\end{array}$ & initial motive for migration: French partner \\
\hline final motive for migration: romantic partner & initial motive for migration: professional opportunity \\
\hline positive experience from education in France & initial motive for migration: desire to gain international experience \\
\hline university degree obtained after their arrival in France & university degree obtained prior to their arrival in France \\
\hline feeling of comfort from the beginning & experienced difficulty to enter social networks including French people \\
\hline positive impact of French partner & $\begin{array}{l}\text { language perceived as a barrier or as important in the process of getting } \\
\text { to know French people and culture }\end{array}$ \\
\hline
\end{tabular}

One important theme when speaking of migratory experience and differences between high and low performers is that of post-secondary education. In contrast with the low performers, several of the high performers had studied for a university degree in France and mention a positive experience from (university) education in France. They report that participating in a French educational program conducted entirely in French, with French people, had given them invaluable opportunities to practice the language, both through extensive reading and teaching and through informal practice with peers.

Another important difference between the high and low performers is related to their experience of the very first years in France. The majority of the high-performing participants, except Lovisa and Lina, explicitly state that they have had a feeling of comfort in France from the beginning. While they certainly express minor frustrations, they appear to have lived with few frictions in their new country, and to have adjusted quite unprob- 
lematically to life in France. The experiences of the low performers are less harmonious. With respect to the social aspect of the migratory experience, three out of four do bring up the difficulty to enter social networks including French people. When asked if she felt it was possible to get access to French contexts during the first year, Lea said it was really difficult. Johanna, when asked what has been most difficult about establishing a life in a new country as an adult, brings up the difficulty of constructing one's social network. Ida brings up a sense of social isolation when describing her first year in France and reports having experienced a strong longing to go back home: It was my first year, and socially it was, I wanted to go back home really really really
really really badly.

A related theme is the perceived link between language proficiency and the possibility of integrating oneself into French social circles and to get to know French culture. Three out of four explicitly state either that the language was a barrier in the process of getting to know French people or emphasize the importance of French language proficiency in the process of making friends and getting to know French culture (Lea, Ida, Johanna). This theme is exemplified by Johanna's comment:

The better I become in French the more sympathetic ... or the more I like the country and the culture ... and it's perhaps ... well, that's how you get to know people. And new cultures. A lot goes through language.

(Johanna)

However, although Ida does describe language as a barrier when attempting to create a social network during the initial phase of the migratory experience, she does not ascribe language any importance at all when asked how important language proficiency has been to her in the process of establishing a life in Paris: "well it's clear, when I think back, 100\% unimportant".

Yet another theme that emerges is the experience that expatriate life offers a sense of freedom at a personal level. This experience is mentioned by all of the participants yet expressed in different terms. For example, Johanna expresses this in the following way:

When you are abroad and you're a foreigner it's more accepted to be different. So there's more room to be who you are somehow [ ... ] in your own culture, cultural expectations come with certain constraints [ ... ] so that's something I appreciate.

(Johanna)

It is interesting to note that this last theme-expatriate life as providing a sense of freedom - is only found among the low performers. A tentative interpretation would be that high performers do not experience the same sense of freedom as the low performers do, because they are more integrated and therefore have probably had to adjust more to the cultural norms of the majority society. This psychological reality cannot be further explored here, but it is truly an interesting finding in relation to different types of migratory experience.

\subsection{Language Use/Social Networks}

As shown in Table 3 below, the high and low performers differ when it comes to patterns of language use. Five out of six high performers report using mainly French in their everyday professional and private life (though this did not exclude L1 Swedish use), while the low performers report mainly using English and or Swedish. As suggested in previous studies, the high performer's frequent and regular target language use plausibly helps explain their high-level performance in L2 French (Flege et al. 1997; Moyer 2004, 2014).

As stated in the background section, research shows that the configuration of one's social network can be an important factor for L2 attainment. In the present study, it is clear that high and low performers differ with respect to their social networks. If we consider the first phase of migration, some high performers report mainly socializing with French people from the beginning, whereas others mainly socialize with Swedish people from the 
beginning and enter, successively, into French-speaking networks. In their current situation, two themes can be found among the high performers: mainly socializing in French and socializing both in French and Swedish, but few of them socialize in internationally mixed networks or using English as a lingua franca. A last recurrent theme is that of actively avoiding co-nationals. Both Leo and Simon state having put this principle into practice in the beginning and Leo explains that he would not have accepted living in France without having French friends.

Table 3. Identified themes in the category "Language use/Social networks".

\begin{tabular}{cc}
\hline \multicolumn{2}{c}{ Category: Language Use/Social Networks } \\
\hline High Performers' Themes & Low Performers' Themes \\
\hline predominantly French use in everyday life & $\begin{array}{c}\text { predominantly English and/or Swedish use in everyday life } \\
\text { socializing mainly with Swedish people and other expats in } \\
\text { the beginning }\end{array}$ \\
$\begin{array}{c}\text { socializing mainly with French people in the beginning } \\
\text { currently socializing mainly with French people and } \\
\text { interacting mainly in French }\end{array}$ & $\begin{array}{c}\text { (for some, including French) } \\
\text { currently socializing with equal proportions of } \\
\begin{array}{c}\text { French-speaking and Swedish-speaking people } \\
\text { actively avoiding co-nationals in the beginning }\end{array}\end{array}$ \\
\hline
\end{tabular}

This is quite different from the low-performing group, which is characterized by their participation in international social networks, some of them including French speakers or French partners, but where the main language of communication is English. The low performers report that they socialize mainly in English and Swedish. This state of affairs can quite obviously be traced back to the differences with respect to motive of migration. Several of the high performers had a pronounced interest in France and the French before coming to France, whereas the low performers did not express any such interest. As will become evident in the next section, social networks are also related to the language learning experience.

\subsection{Language Learning Experience}

Language learning experience being a broad category, it was treated extensively in the interview, and numerous themes emerge (see Table 4 below). The first important difference between the high and the low performers relates to the theme of prior studies in French and the experience thereof. All high performers and half of the low performers studied French in school, but had strikingly different experiences. Most high performers had positive experiences and chose French in a conscious manner, as illustrated by this excerpt of Leo:

It sounded nicer and it was kind of well known that the more ambitious students chose French and lazier ones German, because it had a reputation of being easier, which, later on at more advanced levels, they realized was not true.

As becomes apparent from Leo's interview, French was not only chosen consciously, but actually chosen for "sounding nicer" and for being "more difficult" than German; the challenge was thus a chosen one. In addition, three of the high performers report that they had always had an interest in or liked languages. These educational themes taken together point to a relatively early start with French, a formal base in the language learning experience and often, a conscious choice to study French as well as a pronounced interest in languages. The participant Lina even frankly states that she has an aptitude for languages. A self-reported language learning aptitude is also voiced in similar, although less clear-cut ways by Gunilla and Margareta. For instance, Margareta qualifies herself as a "monkey"- someone who can easily imitate accents and who is eager to do so. As for the low performers, two out of four studied French at school (Ida and Lea). This appears to 
have been more or less of a choice. Lea apparently did not experience learning French to be a choice ("it was really boring but I just had to do it"). The other two, Johanna and Helena, started learning French later in life.

Table 4. Identified themes in the category "Language learning experience".

\begin{tabular}{|c|c|}
\hline \multicolumn{2}{|c|}{ Category: Language Learning Experience } \\
\hline High Performers' Themes & Low Performers' Themes \\
\hline $\begin{array}{c}\text { having studied French at school } \\
\text { having chosen French in a conscious manner } \\
\text { had always had an interest in or liked languages } \\
\text { self-reproted language learning aptitude } \\
\text { university studies in French } \\
\text { self-regulation } \\
\text { agency } \\
\text { extensive media consumption } \\
\text { active listening } \\
\text { efforts to sound like a native speaker } \\
\text { language learning experience perceived } \\
\text { as an enjoyment }\end{array}$ & $\begin{array}{c}\text { having studied French at school } \\
\text { previous international experiences prior to arrival in France } \\
\text { language learning experience perceived as a challenge } \\
\text { attribute themselves responsibility for their language learning outcomes } \\
\text { express having made limited efforts to learn French } \\
\text { agency }\end{array}$ \\
\hline
\end{tabular}

Furthermore, it appears that the language learning process has been a challenge to the low performers, either because of a lack of interest (Lea) or because of experienced difficulties. The low performers, however, seem to differ with respect to how they relate to the difficulty experienced. While Helena expresses acceptance towards her French, which she finds imperfect, Ida appears to be more disturbed by her self-perceived inadequacy in French. Johanna, who had learned both English and Spanish prior to French, declares that she has always had difficulties learning languages: "I've always had a hard time learning languages. It takes a very long time". This is in stark contrast to the high perfomers who, as already mentioned, report being endowed with an aptitude for language learning, enjoyed the language learning process (5 out of 6 ) and found it relatively easy to learn French (at least half of them).

Two other themes that appear relevant when discussing the language learning experience in this group are self-regulation and agency (see Background section). Both groups report clearly experiencing agency in relation to the language learning process, yet the outcomes evidently differ. This can be explained by the practice of self-regulation (or the lack thereof). Simon's self-regulatory behavior can be observed in the following excerpt, where he speaks of a language learning instructor and likens language learning with a game of tennis, and where several aspects of self-regulation are clearly present: making an autonomous decision, being motivated and taking the initiative:

Although I studied five or six years in school, it felt like one never got over some kind of
threshold but with Michael Thomas, I felt quite quickly that I had taken the initiative. I had
the motivation to learn, I was going here and everything went so much quicker. And I got
the confirmation when I came here and started being able to shoot the balls over the net.

(Simon)

While high performers are characterized by making conscious efforts to learn the language, such as taking a job just to speak the language, engaging in massive media consumption and listening actively to conversations in order to imitate the French, low performers admit that they have not made enough efforts to learn the language and attribute themselves responsibility for their limited knowledge of French. It is interesting to observe that the two learner groups share a perception of agency in relation to the language learning process, but that issues such as interest and motivation probably explain the difference both in levels of self-regulation and in learning outcomes.

Related to the theme of self-regulation is the theme of having made efforts to sound like a native speaker. Bearing in mind that all six participants among the high-performing 
participants have "passed as native speakers", it is interesting to hear that at least four out of six have made conscious efforts to sound like a native speaker, and considered this important. This is, by contrast, not reported by any of the low performers.

\subsection{Identity}

The fact that the majority of the participants have made efforts to sound nativelike can also be linked to the category of "Identity", the next category to be discussed (for a summary of the identified themes, see Table 5 below). As stated in the background, the concept can include many components. Here, we will mainly make the distinction between identity issues related to cultural identity and issues related to the self.

Table 5. Identified themes in the category "Identity".

\begin{tabular}{cc}
\hline \multicolumn{2}{c}{ Category: Identity } \\
\hline High Performers' Themes & Low Performers' Themes \\
\hline both Swedish and French position & $\begin{array}{c}\text { both Swedish and French position depending } \\
\text { on context and/or period in life } \\
\text { neither Swedish nor French position } \\
\text { L2 use tied to a sense of loss of self or } \\
\text { personality reduction }\end{array}$ \\
$\begin{array}{c}\text { linguistic competence related to self-value } \\
\text { to integration }\end{array}$ & \\
\hline
\end{tabular}

The quantitative study, preceding this qualitative study, showed that perceived distance to the home country Sweden was related to the extent to which L2 speakers are identified as native speakers of French (see Section 2.1). Examining this then in the interviews, two main orientations can be distinguished: the "both Swedish and French position" and "the neither Swedish nor French position". What is interesting is that these two positions can be found in almost all participants, so it is difficult to distinguish the two learner groups from one another in terms of national identity. It can be concluded that we do not have any cases of learner who identify themselves completely as "Swedish" or completely as "French". Rather, hybridity is the norm in both high and low performers. However, in terms of identity issues related to the self, differences between high and low performers can be discerned.

Most high performers perceive linguistic competence as being essential to integration. Almost all of the high performers (5/6) are affirmative about the important role that language proficiency has played when establishing a life in French society, but some are more explicit about it. The strongest position is advocated by Leo, who also stands out as one of the most self-regulated profiles. He states having had a strong desire to be perceived as French and has consciously wanted to enhance his sense of participation in society. Language has been, according to Leo, key to that.

I don't feel that I would have been comfortable living in a country without speaking the language. I would not have wanted that. Regardless of which country. So, I would have made quite a serious effort to learn the language wherever I would have ended up. It feels like there a lot that goes missing ... almost all culture emanates from the language. If you do not know the language, you miss out on a lot of culture.

Leo thus makes a strong connection between language and culture and experiences the possibility, through language, of taking part in another culture. Lina also thinks passing for a native speaker has been key to her perceived successful integration. To her, language learning takes on an almost existential function. She argues that language proficiency is essential to integration, but also to one's sense of self-respect.:

Lina: But also for my own sake, to prove to myself that I can actually learn how to speak this language [ ... ] That: "I will bloody well be able to do this. I will succeed in speaking, I will, yes ... master this language. As simple as that." 


\section{Interviewer: So some kind of inner driving force?}

Lina: Maybe, well ... what do you call it ... pride? Self-respect of some kind.

Leo expresses something similar when he states that language learning is related to a sense of equality. These driving forces, obtaining a sense of self-respect in the new language, self-satisfaction and ultimately, becoming an equal member of society, have probably had an impact on the efforts made to learn the language, since they are related to the survival of the self during the migratory experience.

A few of the low performers also express the view that language learning is important for integration, but for some, protecting the self appears to have been even more crucial. In Ida's and Helena's account, L2 use is apparently tied to a fear of face loss and in Lea's case, L2 use provokes a sense of personality reduction. In addition to this, two of the four low performers (Ida and Lea) evoke how not mastering French is a way to protect other facets of themselves. Ida expresses this in the following terms: "as long as I don't master the French language I am not stuck". When asked how she explains her self-expressed relatively low ambitions when it comes to learning French, Lea points to a fear that the French language would take over other aspects of herself and her life if it became too prominent in her life, as evidenced in the following excerpt:

Euhm, I don't know, like, partly it's been that I didn't want the French language to take over, it was probably unconscious [... ].

As becomes apparent from Ida's interview, the fact that she has been able to establish a life and a career in France without speaking French has become part of her self-image:

[... ] it's almost like it has become a thing, a part of my character [ ... I I'm the person who has succeeded in living here for almost six and a half years, have made a pretty fun career, down here, without speaking French.

As illustrated by the examples above, L2 proficiency is related to the self and identity. If high performers considered L2 proficiency important for self-respect and self-satisfaction, low performers embrace an identity where L2 proficiency is explicitly unimportant.

\subsection{Attitudes}

The last category to be examined is that of attitudes, here understood as attitudes to the host community, i.e., France. Interestingly enough, this is really the only category where virtually no differences can be discerned between high and low performers (see Table 6 above). In general, all the high-performing participants held positive attitudes to France before moving there and continue to appreciate many sides of life in France. This also goes for the low performers.

Table 6. Identified themes in the category "Attitudes".

\begin{tabular}{cc}
\hline \multicolumn{2}{c}{ Category: Attitudes } \\
\hline High Performers' Themes & Low Performers' Themes \\
\hline $\begin{array}{c}\text { appreciation of a tolerant intellectual climate } \\
\text { appreciating the diversity in French society } \\
\text { appreciation for the French way of life } \\
\text { missing the Swedish social model }\end{array}$ & $\begin{array}{c}\text { appreciation of free, permissive intellectual climate } \\
\text { appreciation for the French way of life }\end{array}$ \\
\hline
\end{tabular}

Three recurrent subthemes can be distinguished among the positive attitudes: an appreciation of a tolerant intellectual climate, which can be noted among almost all participants. It seems like the French virtue of freedom of speech is actually experienced by the high-performing participants in our group.

Another theme that stands out is that of appreciating the diversity in French society. Diversity seems to be interpreted in several ways here: diversity in relation to the theme above, i.e., viewpoint diversity in discussions, but also in relation to ethnic diversity. 
A third and quite prominent theme is that of appreciating all things related to good life in France. The gastronomic culture, the beauty of buildings and objects and the landscapes are among the aspects mentioned.

On a more negative note, relating to what participants find to be missing in France when compared to their home country Sweden, some among both the high and low performers mention concepts such as equality, gender equality and solidarity. It is interesting that participants find those features lacking in their new host country that might be considered the most characteristic of Swedish society, at least according to a stereotypical image of "the Swedish Model".

\section{Discussion and Conclusions}

The present study set out to explore what social and psychological factors can explain high performance in second language acquisition in a migratory context, based on a thematic analysis of in-depth interviews with linguistically high- and low-performing L2 learners of French. A preceding quantitative study on 62 participants had shown that language aptitude (as assessed by the LLAMA test) and acculturation (as assessed by the VIA questionnaire) were predictive factors in explaining perceived nativelikeness (Forsberg Lundell et al. forthcoming). The present study constitutes a follow-up to the quantitative study with the aim of exploring whether other factors (of which some were not considered in the quantitative analysis), may help explain successful late L2 acquisition. The following five factors/categories were investigated: migratory experience, language use/social networks, language learning experience, identity and attitudes.

First of all, the analysis suggests that the high-performing and low-performing participants are similar with respect to one theme and that is "attitudes to the French and France". Both groups generally hold positive views towards their country of migration. This is interesting, since one could imagine, as has long been suggested in the literature, from Schumann (1976) to Gardner (Masgoret and Gardner 2003), that positive attitudes to the host community will influence language learning favourably. Nevertheless, the participants display clear differences on almost all of the other categories.

The first category that clearly separates high performers from low performers is that of language learning experience and particularly the themes of self-reported language aptitude and language interest, which are both characteristic of the high performers. The importance of aptitude for attaining nativelike command of the L2 is strengthened by the frank statements made by some of the low-performing participants who claim that they have always found it difficult to learn languages, not only French. One could accordingly say that one of the main results from the quantitative analysis-that aptitude is a reliable predictor of perceived nativelikeness-is supported by the participants' narratives in the present study. Furthermore, the high performers are also characterized by more formal learning of French-although a few low performers have studied to the same extent as some high performers, they report negative attitudes to French learning in school, whereas the high performers generally report positive experiences. Furthermore, in contrast to the low-performing group, the high performers display self-regulated language learning behavior (cf. Moyer 2014) and have mostly enjoyed language learning (cf. Muñoz 2014). Another striking feature of the high-performing group is that several of the participants voice the importance of passing for a native speaker, not least for existential reasons and to feel entirely part of French society. The importance of language learning for one's sense of equality and self-respect are less frequently discussed in the literature and would be worthwhile exploring further in future research (but see Lybeck 2002 and Moyer 2004). None of the low performers report having ever had a particular interest in the French language or a strong desire to master French. As opposed to the high performers, they found it difficult to learn French, a difficulty which they attribute to their lack of interest or to their self-image as bad language learners. In addition, some of them seem to perceive French language learning as a threat to their identity, and one low performer appears to have created an identity around being a non-proficient French speaker. 
Language use and social networks is another category that distinguishes the high performers from the low performers. Several of the high performers report finding it relatively easy to enter social networks including French, already from the beginning of their stay in France. This naturally gave them rich opportunities to practice their French in social interaction. The observation that extensive L2 use and social relations with native speakers favor L2 development is in line with previous research stemming both from a migratory context (Dollmann et al. 2020; Flege et al. 1997; Lybeck 2002; Moyer 2004) and a Study Abroad context (Dewey et al. 2013; Mitchell et al. 2017). Some of the high performers even report having consciously avoided co-nationals-a rather extreme stance which they themselves justify by their strong desire to improve. In contrast, low-performing participants report having had difficulties creating social networks with French people and/or having rather formed Swedish- and English-speaking social networks. Interestingly, if the low performers engage mainly in social networks in English, the high performers report little use of English in general. It thus seems like recourse to English can actually constitute an obstacle to French language learning.

High performers and low performers differ on many parameters, but can we, among these, discern any main decisive features? Our tentative summary would be that most of the high-performing participants in our population have an aptitude and a specific interest in languages as a starting point, leading to extensive use and practice in French, combined with self-regulatory behaviors and a determination to attain nativelike proficiency (cf. Moyer 2004). This also aligns, to a certain extent, with the results on formal language learners from Busse and Williams (2010), Muñoz (2014) and Stolte (2015).

However, a few limitations also need to be acknowledged. The current study is based on an uneven number of learners representing each case, which may somewhat skew the observations. The thematic analysis is inevitably the result of the researchers' interpretations. However, this study throws light on what circumstances, experiences and characteristics promote high performance in an L2 among adult migrants.

Last, the importance of different cultural contexts and socio-political environments should not be neglected. France is clearly a language learning environment where assimilationist and nationalist values are common in the official arena and where language is highly related to social hierarchies. This will, most probably, play a role in the effort learners will expand to learn a language and, in some cases, how well they finally learn to master their L2. This points to the importance of including (language) ideologies in future studies and also to the necessity to replicate this study in another linguistic and cultural context, in order to gain a more complete understanding of the decisive factors for adult SLA.

Author Contributions: Conceptualization, F.F.L. and K.A.; Methodology, F.F.L. and K.A.; formal analysis, F.F.L. and K.A.; data curation, F.F.L. and K.A.; writing-original draft preparation, F.F.L. and K.A.; writing-review and editing, F.F.L. and K.A.; project administration, F.F.L.; funding acquisition, F.F.L. All authors have read and agreed to the published version of the manuscript.

Funding: This research was funded by The Swedish Research Council, (Vetenskapsrådet), grant number 2017-01196.

Institutional Review Board Statement: The study was conducted according to the guidelines of the Declaration of Helsinki, and approved by the Swedish Board of Ethical Review (Regionala etikprö̈ningsnämnden i Stockholm, Diary number 2018/2019-31/5).

Informed Consent Statement: Informed consent was obtained by all the participants in the present study.

Data Availability Statement: The data presented in this study are available on request from the corresponding author. The data are not publicly available due to ethical reasons.

Acknowledgments: The authors wish to express their deep gratitude to all the participants that agreed to participate in this study. In addition, they are deeply grateful to the anonymous reviewers who provided insightful and constructive comments. 
Conflicts of Interest: The authors declare no conflict of interest. The funding sponsors had no role in the design of the study; in the collection, analyses, or interpretation of data; in the writing of the manuscript, or in the decision to publish the results.

\section{References}

Abrahamsson, Niclas, and Kenneth Hyltenstam. 2009. Age of onset and nativelikeness in a second language: Listener perception versus linguistic scrutiny. Language Learning 59: 249-306. [CrossRef]

Bandura, Albert. 1991. Social cognitive theory of self-regulation. Organizational Behavior and Human Decision Processes 50: $248-87$. [CrossRef]

Benson, Phil, Gary Barkhuizen, Peter Bodycott, and Jill Brown. 2013. Second Language Identities in Narratives of Study Abroad. London: Palgrave Macmillan.

Braun, Virginia, and Victoria Clarke. 2006. Using thematic analysis in psychology. Qualitative Research in Psychology 3: 77-71. [CrossRef]

Busse, Vera, and Marion Williams. 2010. Why German? Motivation of students studying German at English universities. The Language Learning Journal 38: 67-85. [CrossRef]

De Fina, Anna, and Amelia Tseng. 2017. Narratives in the study of migrants. In The Routledge Handbook of Migration and Language. Edited by Suresh Canagarajah. New York: Routledge, pp. 381-96.

Dewaele, Jean-Marc, Peter D. MacIntyre, Carmen Boudreau, and Livia Dewaele. 2016. Do girls have all the fun? Anxiety and enjoyment in the foreign language classroom. Theory and Practice of Second Language Acquisition 2: 41-63.

Dewaele, Jean-Marc, John Witney, Kazuya Saito, and Livia Dewaele. 2018. Foreign language enjoyment and anxiety: The effect of teacher and learner variables. Language Teaching Research 22: 676-97. [CrossRef]

Dewey, Dan P., Kirk R. Belnap, and Hillstrom Rebecca. 2013. Social network development, language use, and language acquisition during study abroad: Arabic language learners' perspectives. Frontiers: The Interdisciplinary Journal of Study Abroad 22: 84-110. [CrossRef]

Diskin, Chloé, and Vera Regan. 2015. Migratory experience and second language acquisition among Polish and Chinese migrants in Dublin, Ireland. In Cultural Migrants and Optimal Language Acquisition. Edited by Fanny Forsberg Lundell and Inge Bartning. Bristol: Multilingual Matters, pp. 137-77.

Dollmann, Jörg, Irena Kogan, and Markus Weißmann. 2020. Speaking accent-free in L2 beyond the critical period: The compensatory role of individual abilities and opportunity structures. Applied Linguistics 41: 787-809. [CrossRef]

Dörnyei, Zóltan. 2010. The relationship between language aptitude and language learning motivation: Individual differences from a dynamic systems perspective. In The Continuum Companion to Second Language Acquisition. Edited by Ernesto Macaro. New York: Continuum International, pp. 247-67.

Douglas Fir Group. 2016. A transdisciplinary framework for SLA in a multilingual world. The Modern Language Journal 100: 19-4. [CrossRef]

Duff, Patricia A., and Steven Talmy. 2011. Language socialization approaches to second language acquisition. Social, cultural, and linguistic development in additional languages. In Alternative Approaches to Second Language Acquisition. Edited by Dwight Atkinson. New York: Routledge, pp. 95-116.

Flege, James E., Elaina M. Frieda, and Takeshi Nozawa. 1997. Amount of native-language (L1) use affects the pronunciation of an L2. Journal of Phonetics 25: 169-86. [CrossRef]

Forsberg Lundell, Fanny, Christina Lindqvist, and Amanda Edmonds. 2018. Productive collocation knowledge at advanced CEFR levels: Evidence from the development of a test for advanced L2 French. Canadian Modern Language Review 74: 637-49. [CrossRef]

Forsberg Lundell, Fanny, Klara Arvidsson, and Andreas Jemstedt. forthcoming. What factors predict perceived nativelikeness in long-term L2 users? submitted.

Gardner, Robert C. 2006. The socio-educational model of second language acquisition: A research paradigm. EUROSLA Yearbook 6: 237-60. [CrossRef]

Gatbonton, Elisabeth, and Pavel Trofimovich. 2008. The ethnic group affiliation and L2 proficiency link: Empirical evidence. Language Awareness 17: 229-48. [CrossRef]

Granena, Gisela, and Michael Long. 2013. Introduction and overview. In Sensitive periods, language aptitude, and ultimate L2 attainment. Edited by Gisela Granena and Michael Long. Amsterdam: John Benjamins, pp. IX-XVIII.

Hyltenstam, Kenneth. 2018. Second language ultimate attainment: Effects of maturation, exercise and social/psychological factors. Bilingualism: Language and Cognition 21: 921-23. [CrossRef]

Isabelli-García, Christina. 2006. Study abroad social networks, motivation and attitudes: Implications for second language acquisition. In Language Learners in Study Abroad Contexts. Edited by MargaretA. DuFon and Eton Churchill. Clevedon: Multilingual Matters, pp. 231-58.

Kinginger, Celeste. 2013. Identity and language learning in Study Abroad. Foreign Language Annals 46: 339-58. [CrossRef]

Kinsella, Ciara, and David Singleton. 2014. Much more than age. Applied Linguistics 35: 441-62. [CrossRef]

Kormos, Judit, Thom Tiddle, and Kata Csizér. 2011. Systems of goals, attitudes, and self-related beliefs in second language learning. Applied Linguistics 32: 495-516. [CrossRef]

Lybeck, Karen. 2002. Cultural identification and second language pronunciation of Americans in Norway. The Modern Language Journal 86: 174-91. [CrossRef] 
MacIntyre, Peter D., and Catherine Charos. 1996. Personality, attitudes, and affect as predictors of second language communication. Journal of Language and Social Psychology 15: 3-26. [CrossRef]

Masgoret, Anne-Marie, and Robert C. Gardner. 2003. Attitudes, motivation, and second language learning. A meta-analysis of studies conducted by Gardner and associates. Language Learning 53: 123-63. [CrossRef]

McManus, Kevin, Rosamund Mitchell, and Nicole Tracy-Ventura. 2014. Understanding insertion and integration in a study abroad context: The case of English-speaking sojourners in France. Revue Française de Linguistique Appliquée 19: 97-116. [CrossRef]

Meara, Paul. 2005. LLAMA Language Aptitude Tests. Swansea: Lognostics.

Milroy, Lesley. 1980. Language and Social Networks. Oxford: Blackwell.

Mitchell, Rosamond, Nicole Tracy-Ventura, and Kevin McManus. 2017. Anglophone Students Abroad. Identity, Social Relationships and Language Learning. New York: Routledge.

Moyer, Alene. 2004. Age, Accent and Experience in Second Language Acquisition. Bristol: Multilingual Matters.

Moyer, Alene. 2014. Exceptional outcomes in L2 phonology: The critical factors of learner engagement and self-regulation. Applied Linguistics 35: 418-40. [CrossRef]

Muñoz, Carmen. 2014. Starting age and other influential factors: Insights from learner interviews. Studies in Second Language Learning and Teaching 3: 465-84. [CrossRef]

Muñoz, Carmen, and David Singleton. 2011. A critical review of age-related research on L2 ultimate attainment. Language Teaching 44: 1-35. [CrossRef]

Naiman, Neil, Maria Fröhlich, H. H. Stern, and Angie Todesco. 1978. The Good Language Learner. Toronto: Ontario Institute for Studies in Education.

Norton, Bonnie. 2014. Idnetity and poststructuralist theory in SLA. In Multiple Perspectives on the Self in SLA. Edited by Sarah Mercer and Marion Williams. Bristol: Multilingual Matters, pp. 59-74.

Ryder, Andrew G., Lynn E. Alden, and Delroy L. Paulhus. 2000. Is acculturation unidimensional or bidimensional? A head-to-head comparison in the prediction of personality, self-identity, and adjustment. Journal of Personality and Social Psychology 79: 49-65. [CrossRef] [PubMed]

Schumann, John. 1976. Second language acquisition: The pidiginization hypothesis. Language Learning 26: 391-40. [CrossRef]

Stolte, Rosemarie. 2015. German Language Learning in England. Understanding the Enthusiasts. Unpublished Ph.D. dissertation, University of Southampton, Southampton, UK.

van der Zee, Karen, Jan Pieter van den Oudenhouven, Joseph G. Ponterotto, and Alexander W. Fietzer. 2013. Multicultural personality questionnaire: Development of a short form. Journal of Personality Assessment 95: 118-24. [CrossRef] [PubMed] 